\title{
Antigen-presenting cell-derived complement modulates graft-versus-host disease
}

\author{
Wing-Hong Kwan,, ${ }^{1,2}$ Daigo Hashimoto, ${ }^{3}$ Estela Paz-Artal,, ${ }^{1}$ Katya Ostrow, ${ }^{1}$ Melanie Greter, ${ }^{2,3}$ \\ Hugo Raedler, ${ }^{1}$ M. Edward Medof, ${ }^{4}$ Miriam Merad,, ${ }^{2,3}$ and Peter S. Heeger ${ }^{1,2,5}$
}

\begin{abstract}
${ }^{1}$ Department of Medicine, 2 Immunology Institute, and ${ }^{3}$ Department of Oncological Sciences and Tisch Cancer Institute, Mount Sinai School of Medicine, New York, New York, USA. ${ }^{4}$ Institute of Pathology, Case Western Reserve University, Cleveland, Ohio, USA. ${ }^{5}$ Recanati Miller Transplant Institute, Mount Sinai School of Medicine, New York, New York, USA.
\end{abstract}

\begin{abstract}
Acute graft-versus-host disease (GvHD) is a serious complication of allogeneic hematopoietic cell transplantation (allo-HCT) that results from donor allogeneic $T$ cell attack on host tissues. Based on previous work implicating immune cell-derived C3a and C5a as regulators of T cell immunity, we examined the effects of locally produced C3a and C5a on murine T cell-mediated GvHD. We found that total body irradiation, a conditioning regimen required to permit engraftment of allo-HCT, caused upregulation and activation of alternative pathway complement components by recipient APCs. Allo-HCT with decay accelerating factor-null (Daf1 $\left.{ }^{-/-}\right)$ host BM and $\mathrm{Daf1} 1^{-/-}$donor lymphocytes led to exacerbated GvHD outcome and resulted in splenic and organinfiltrating $\mathrm{T}$ cell expansion. $\mathrm{T}$ cells deficient in $\mathrm{C} 3 \mathrm{a}$ receptor $(\mathrm{C3aR})$ and/or $\mathrm{C5}$ a receptor $(\mathrm{C5} \mathrm{aR})$ responded weakly in allogeneic hosts and exhibited limited ability to induce GvHD. Using a clinically relevant treatment strategy, we showed that pharmacological C5aR blockade reduced GvHD morbidity. Our data mechanistically link APC-derived complement to $\mathrm{T}$ cell-mediated GvHD and support complement inhibition as a therapeutic strategy for GvHD in humans.
\end{abstract}

\section{Introduction}

Graft-versus-host disease (GvHD) - a potentially lethal complication of allogeneic hematopoietic cell transplantation (allo-HCT), which is performed to treat malignancies or nonmalignant conditions - is initiated by cognate interactions between donor $\mathrm{T}$ cells and host, MHC-disparate, or minor antigen-disparate (mH-disparate) DCs (1-4). Total body irradiation (TBI), a requirement in allo-HCT, activates recipient DCs through incompletely deciphered mechanisms (4-6) and facilitates alloreactive $\mathrm{T}$ cell activation. Subsequent costimulatory and TCR-initiated signaling pathways orchestrate pathogenic alloresponses $(7,8)$, but emerging evidence indicates that innate mechanisms influence the strength of GvHDinducing $\mathrm{T}$ cell immunity $(9,10)$.

Previous work by our laboratories showed that DCs and T cells synthesize and secrete complement proteins; that these cells express C3a receptor (C3aR), C5a receptor (C5aR), and complement regulators on their surfaces; and that locally produced $\mathrm{C} 3 \mathrm{a}$ and $\mathrm{C} 5 \mathrm{a}$ influences the strength/phenotype of $\mathrm{T}$ cell responses (11-13). These findings raise the possibility that C3a and/or C5a modulate $\mathrm{T}$ cell-induced GvHD and that targeting C3aR/C5aR signaling could be therapeutically efficacious.

\section{Results and Discussion}

We examined the effect of TBI used for allo-HCT on the synthesis of complement components by recipient APCs. Compared with nonirradiated controls, DCs and macrophages isolated 3-24 hours after TBI produced up to 40-fold more mRNA for C3, C5, factor $\mathrm{B}$, and factor D (Figure 1, A and B). Immunoblots performed on DC lysates confirmed that TBI upregulated C3 protein (Figure 1C). Irradiation lowered DC expression of decay accelerating fac-

Authorship note: Miriam Merad and Peter S. Heeger are co-senior authors. Conflict of interest: The authors have declared that no conflict of interest exists. Citation for this article: J Clin Invest. 2012;122(6):2234-2238. doi:10.1172/JCI61019. tor (DAF, also referred to as CD55; Figure 1D), a surface-expressed complement regulator that prevents amplification of the complement cascade at the C3 convertase step (14). The lowered DAF expression lifted restraint on activation of the DC-derived complement proteins; we detected more C5a in serum-free culture supernatants obtained from DCs of irradiated mice (Figure 1E). To test for functional effects, we performed in vitro mixed lymphocyte reactions using splenic DCs isolated before and after TBI (Figure $1, \mathrm{~F}$ and $\mathrm{G})$. T cells responded most strongly to allogeneic DCs obtained from irradiated mice, but responses were prevented in cultures containing C3/C5-deficient DCs. Splenic macrophages do not induce allogeneic $T$ cell expansion (15). In vivo $T$ cell alloreactivity was also reduced in irradiated $\mathrm{BALB} / \mathrm{c}$ recipients reconstituted with $\mathrm{C} 3 / \mathrm{C} 5$-deficient BM, in which C3/C5 deficiency was restricted to the host hematopoietic compartment (Supplemental Figure 1; supplemental material available online with this article; doi:10.1172/JCI61019DS1). Thus, C3/C5 produced by host hematopoietic cells controlled allogeneic $\mathrm{T}$ cell reactivity upon allo-HCT. To test for effects on GvHD, we used DAF-deficient (Daf1-/-) mice, in which restraint on local C3a/C5a production is lifted (13). We transplanted B6 Daf1 $1^{-/-}$mice with MHC-disparate Daf1 ${ }^{-/}$ BALB/c BM plus 2 different doses of Daf1-/- BALB/c splenocytes (Figure 2, A-C). We observed worse clinical (Figure 2, A and B) and histological GvHD scores in Daf1 ${ }^{-/-}$recipients (large bowel, WT, $0.25 \pm 0.1 ;$ Daf1 $1^{--}, 2.8 \pm 0.2 ; P<0.05 ; n=4$ per group; data not shown). Flow cytometry of spleens of $\mathrm{Daf1}^{-/-}$recipients showed approximately 5 -fold more IFN- $\gamma^{+} \mathrm{T}$ cells (Figure $2 \mathrm{C}$ ).

To examine the role of recipient DAF in protecting against GvHD, we transplanted WT or Daf1 $1^{-/}$B 6 mice with BALB/c BM and spleen cells. We found that $D a f 1^{-/-}$recipients had reduced survival (Figure 2D) and worsened clinical scores (Supplemental Figure 2A) versus WT recipients. We also observed enhanced proliferation/expansion of naive and in vitro-primed T cells 5 days after transfer into irradiated $\mathrm{Daf1}^{-/-}$allogeneic hosts (Sup- 
A

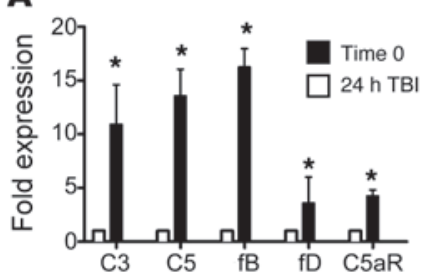

D

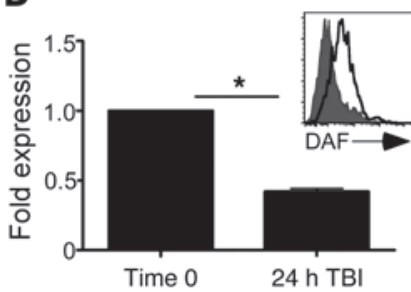

B

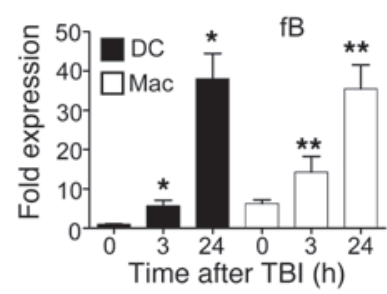

E

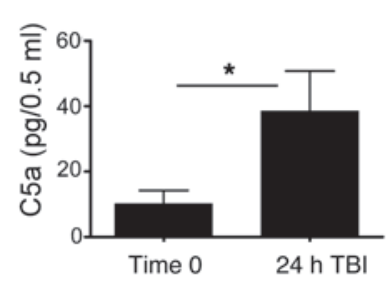

C

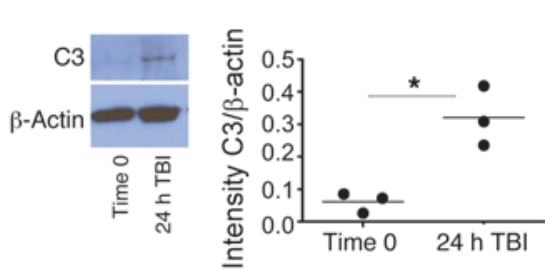

G

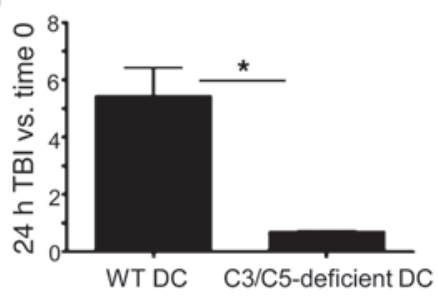

Figure 1

TBI causes DC complement upregulation and complement-dependent augmentation of T cell reactivity. (A) Quantitative PCR for complement components performed on splenic DC mRNA purified from B6 mice before (time 0) or 24 hours after TBI. fB, factor B; fD, factor D. (B) Kinetics of gene expression in splenic DCs or macrophages obtained from untreated or TBI-treated mice. Experiments were performed in triplicate. (C) Representative immunoblot for C3 (and $\beta$-actin control) performed on lysates of splenic DCs isolated before or 24 hours after TBI. Quantitative densitometry $(n=3)$ normalized to $\beta$-actin is also shown. (D) Quantitative PCR for DAF and expression of DAF assessed by flow cytometry (inset) on splenic DCs isolated from untreated (solid line) or TBI-treated (24 hours; filled) B6 mice. Each experiment in A-D was repeated twice with similar results. (E) C5a ELISA, performed on supernatants of unstimulated splenic DCs obtained from untreated or TBI-treated (24 hours) B6 mice, pooled from 4 experiments. (F) Representative CSFE dilution plots of B6 T cells mixed with allogeneic $\mathrm{H}-2^{d} \mathrm{WT}$ or C3/C5-deficient splenic DCs obtained from untreated or TBI-treated mice. (G) Quantification of proliferation ( $>4$ divisions), calculated as the ratio of response to DCs from irradiated mice to that from nonirradiated mice, and expressed as a percentage. Data are representative of 2 different experiments. ${ }^{\star} P<0.05$.

plemental Figure 3, A and B). Thus, recipient DAF deficiency augmented $\mathrm{T}$ cell alloreactivity during priming and reactivation. Host DAF deficiency also worsened GvHD in a $\mathrm{mH}$-disparate combination (C3H.SW $\rightarrow$ B6; Supplemental Figure 3C).

To distinguish the contribution of host hematopoietic cellexpressed DAF on GvHD, we generated BM chimeric mice reconstituted with congenic Daf1 $1^{-/}$or WT BM to use as recipients. Control experiments showed equal reconstitution of donor-derived hematopoietic cells in blood 14 days posttransplant (WT, 81\%; Daf1 $1^{-/}, 84 \% ; P=\mathrm{NS} ; n=4$ per group), which indicates that DAF deficiency did not affect engraftment. At 8 weeks after reconstitution, chimeric mice were irradiated and injected with BALB/c BM and splenocytes. We observed worse GvHD in Daf1-/- BM chimeric mice (Figure 2E), which suggests that DAF deficiency on host hematopoietic cells was responsible for the increased alloreactivity observed in Daf1 $1^{-/-}$animals.

To assess the contribution of donor cell DAF in protecting against GvHD, we transplanted BALB/c recipients with B6 WT or Daf1-/$\mathrm{BM} /$ spleen cells. Recipients injected with $\mathrm{Daf1} 1^{-/}$cells developed exacerbated weight loss and shorter survival (Figure $2 \mathrm{~F}$ ) and contained greater numbers of skin-infiltrating donor T cells (Figure $2 \mathrm{G}$ ) with increased staining for $\mathrm{C} 3 \mathrm{~d}$ in the skin at sites of cell infiltration (Supplemental Figure 2, B and C) 21 days posttransplant. The same result was observed with the $\mathrm{B} 6 \rightarrow \mathrm{C} 3 \mathrm{H}$.SW, $\mathrm{mH}$-disparate combination (WT, $87 \%$ of baseline weight at 21 days posttransplant; Daf1 $1^{-/}$, $73 \% ; P<0.05 ; n=5$ per group; data not shown).

Since irradiation triggered DC complement production (Figure $1)$, activation of which is enhanced by DAF deficiency $(11,13,16)$, we postulated that the increased C3a/C5a would exacerbate GvHD in part via $\mathrm{C} 3 \mathrm{aR} / \mathrm{C} 5 \mathrm{aR}$ signaling on responder $\mathrm{T}$ cells. To test this hypothesis, we reconstituted irradiated $\mathrm{BALB} / \mathrm{c}$ mice with $\mathrm{B} 6 \mathrm{BM}$

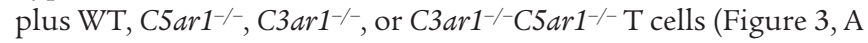
and B). The clinical/pathological expression of GvHD was diminished in $\mathrm{BALB} / \mathrm{c}$ recipients of $\mathrm{B} 6 \mathrm{C} 3 \mathrm{arl}^{-/-} \mathrm{C} 5 \mathrm{ar} 1^{-/-} \mathrm{T}$ cells (large bowel scores, WT, $6.0 \pm 2.2$; $\mathrm{C} 3 \mathrm{arl}^{-/-} \mathrm{C} 5 \mathrm{arl}^{-/-}, 2.6 \pm 1.5 ; \mathrm{P}<0.05$; $n=8$ per group pooled from 2 experiments). We observed partial protection from GvHD in recipients of either $\mathrm{C}_{5} \mathrm{arl}^{-\gamma_{-}^{-}}$(Figure 3A) or C3ar1 ${ }^{-/-} \mathrm{T}$ cells (Supplemental Figure 4), indicative of overlapping, but not fully redundant, effects.

To further assess the role of T cell-expressed C3aR/C5aR, we used a competition strategy. We reconstituted irradiated $\mathrm{BALB} / \mathrm{c}$ recipients with $\mathrm{B} 6$ allogeneic BM plus equal numbers of B6 CD $45.1^{+} \mathrm{WT}$, B6 CD 45.2 $2^{+} \mathrm{C}_{\text {arr }}$-/-C5ar1 $^{-/-}$, and B6 Thy1.1 Daf1 $1^{-/} \mathrm{T}$ cells. After 5 weeks, we compared the expansion/infiltration of each congeneic $\mathrm{B} 6 \mathrm{~T}$ cell population in the same recipient animal (Figure 3C and Supplemental Figure 5). We observed fewer $\mathrm{C} \mathrm{arr}^{-1-} \mathrm{CS}_{\mathrm{ar} 1^{-/}}$than WT T cells, and more Daf1 ${ }^{-1-} \mathrm{T}$ cells, in recipient skin and large bowel (Figure 3, C and D). Together, these data indicate that $\mathrm{T}$ cell expression of $\mathrm{DAF}, \mathrm{C} 3 \mathrm{aR}$, and $\mathrm{C} 5 \mathrm{aR}$ regulate in vivo $\mathrm{T}$ cell alloreactivity during GvHD.

To develop a treatment strategy, we examined the effect of C5aR blockade on GvHD. Continuous 30-day infusion of a specific cyclic-peptide C5aR antagonist (C5aR-A) by osmotic pump (17) starting 7 or 14 days posttransplant (after initiation of GvHDinduced weight loss) improved the clinical manifestations of $\mathrm{GvHD}$ in $\mathrm{BALB} / \mathrm{c}$ recipients of $\mathrm{B} 6$ cells (Figure $3 \mathrm{E}$ ). In the $\mathrm{mH}$ disparate $\mathrm{B} 6 \rightarrow \mathrm{C} 3 \mathrm{H} . \mathrm{SW}$ combination, C5aR-A administration prevented the exacerbated disease induced by Daf1 $1^{-/-}$compared 

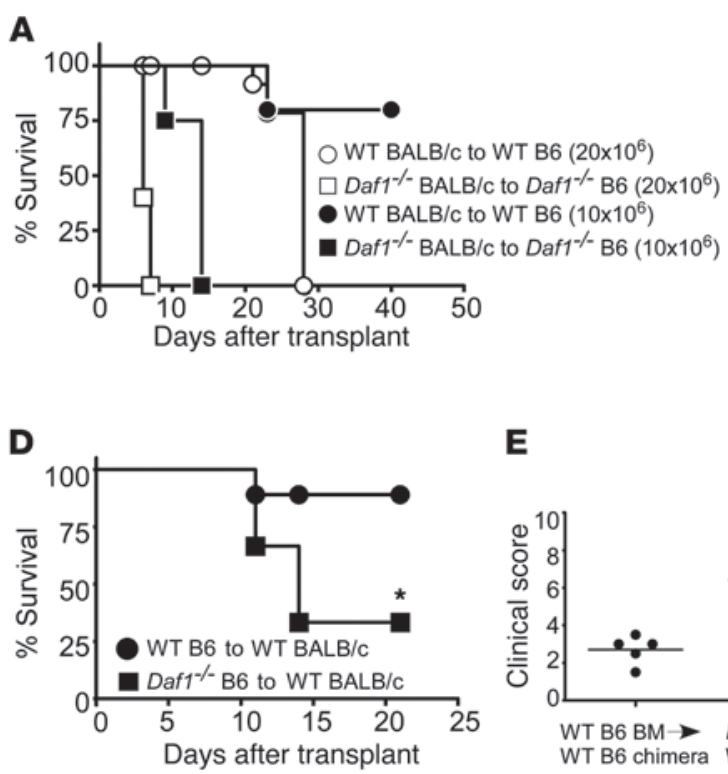
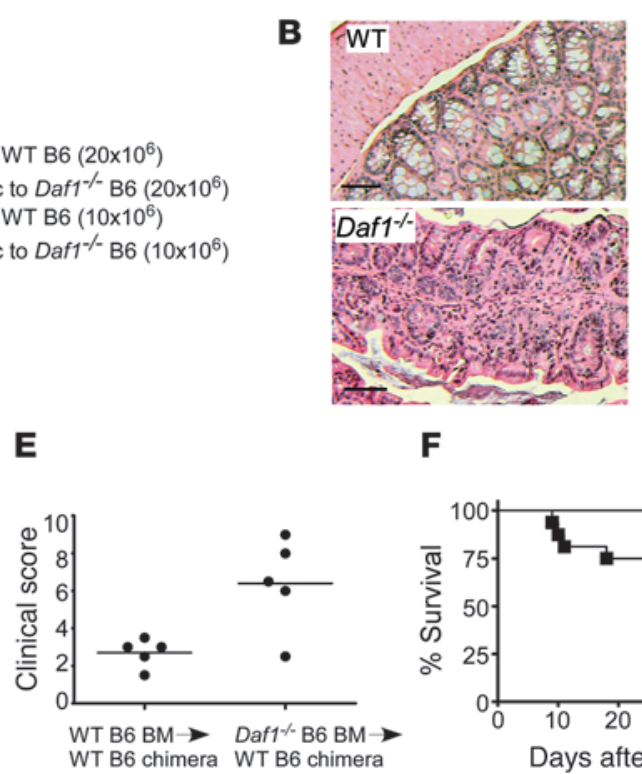

$\mathbf{F}$

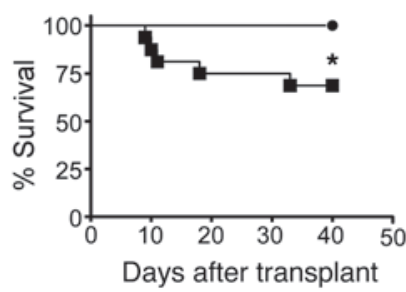

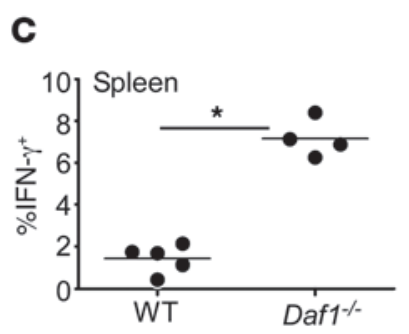

G

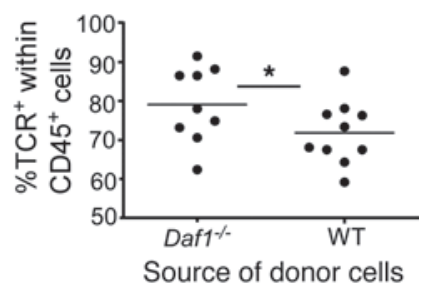

Figure 2

DAF deficiency exacerbates GvHD. (A-C) GvHD in WT B6 recipients of WT BALB/c transplants or Daf1 ${ }^{-/-}$B6 recipients of Daf1-/- BALB/c transplants. (A) Survival curves for $10 \times 10^{6}$ or $20 \times 10^{6}$ doses of donor spleen cells. $n=5$ per group. (B) Representative H\&E-stained bowel tissue (8 days posttransplant) from a separate experiment $\left(5 \times 10^{6}\right.$ donor spleen cells). Scale bars: $50 \mu \mathrm{m}$. (C) IFN- $\gamma$-producing spleen cells stimulated ex vivo with $\alpha$ CD3/CD28 (day 8 posttransplant). (D) Survival in WT or Daf1-l- B6 recipients transplanted with WT BALB/c BM plus $1 \times 10^{6}$ BALB/c spleen cells. $n=5$ per group, repeated with the same results. (E) Clinical GvHD scores in B6 chimeras of allogeneic BALB/c BM transplants. Shown are pooled data from 2 separate experiments $(n=10$ per group). (F and $\mathbf{G})$ WT BALB/c mice received B6 WT or Daf1-/- T cell-depleted BM plus $0.5 \times 10^{6}$ B6 WT or Daf1 $1^{-1}$ splenocytes. (F) Survival ( $n=15$ per group, pooled from 3 experiments). (G) Percent skin-infiltrating T cells at 5 weeks, pooled from 2 experiments. ${ }^{*} P<0.05$.

with WT donor cells (Figure 3F), which indicates that the effects of DAF deficiency are dependent in part on C5a. Whether shortterm C5aR blockade prevents late GvHD and/or induces immune tolerance requires further study.

Our results indicated that APC-expressed DAF, through controlling local $\mathrm{C} 3 \mathrm{a} / \mathrm{C} 5 \mathrm{a}$ production, regulated $\mathrm{T}$ cell-dependent GvHD. We showed that TBI-induced APC activation was dependent on APC-produced C3/C5 (Figure 1), providing a molecular explanation for observations by others that irradiation-induced, gut-derived LPS modulates APC maturation $(18,19)$. LPS induces complement production by DCs (20), complement amplifies TLR signals $(21,22)$, and $T$ cells respond weakly to allogeneic, LPS-stimulated DCs from $C 3^{-/-}$mice $(13,16,20)$. Thus, while gutderived LPS may contribute to DC maturation after TBI, our data suggest that the effects are dependent upon immune cell-derived complement activation. Because previous work showed that radioresistant DCs drive $\operatorname{GvHD}(1,3,4)$ and that host macrophages can be protective (15), our findings strongly implicate DCs as the primary, pathogenic source of complement following TBI.

While serum complement could contribute to the observed effects on alloreactive $T$ cells, several of our observations support the conclusion that the mechanisms involve immune cell-derived complement: (a) DAF deficiency on donor T cells augmented T cell expansion, while (b) $\mathrm{C} \mathrm{ar} 1^{-/-} \mathrm{C} 5 \mathrm{arl}^{-/-} \mathrm{T}$ cells expanded minimally in the same host, and (c) in vivo $\mathrm{T}$ cell alloresponses were modulated by BM cell-derived C3/C5 and DAF. Finally, as we showed that $\mathrm{C} 5 \mathrm{aR}$ blockade treated murine GvHD (Figure 3), our data support the need for studies to assess the efficacy of analogous strategies in humans.

\section{Methods}

Mice. C57BL/6 (B6), $\mathrm{C3}^{---}$, and C3.SW mice (all H2 ${ }^{b}$ ) and $\mathrm{C}^{\mathrm{ar} 1^{-/-}}$, B10.D2 $\mathrm{Hc}^{0}$ (C5-deficient), B10.D2 $\mathrm{Hc}^{1}(\mathrm{C} 5+)$, and BALB/c mice (all $\mathrm{H}-2^{d}$ ) were purchased from The Jackson Laboratory. See Supplemental Methods for sources and intercrossing strategies for other congenic and knockout mice. allo-HCT and GvHD. allo-HCT was performed as described previously (3). Survival after allo-HCT was monitored daily, and clinical GvHD scores (23) were assessed weekly. See Supplemental Methods for details.

Antibodies and reagents. All antibodies were purchased from BD Biosciences - Pharmingen, with the exception of TCR- $\beta$, CD 45.1, and CD45.2 (ebioscience). CFSE was obtained from Invitrogen. C5aR-A [Ac-Phe-cyclo(Orn-Pro-dCha-Trp-Arg)] was synthesized by GenScript and delivered by subcutaneous osmotic pump (Alzet) that functions for approximately 30 days.

Preparation of single-cell suspensions and flow cytometry. Spleen and skin preparations were incubated in RPMI 1640 containing 10\% fetal bovine serum and collagenase type IV $(0.2 \mathrm{mg} / \mathrm{ml}$; Sigma-Aldrich) and passed through a $70-\mu \mathrm{m}$ strainer. Isolation of gut immune cells was adapted from previously published methods (24).

In vitro cell culture assays. $2 \times 10^{4}$ magnetic bead-isolated (Miltenyi), CFSElabeled $\mathrm{CD}^{+} \mathrm{T}$ cells were cultured with DCs in 96-well plates. Samples were stained for TCR- $\beta$ and DAPI, collected using FACS Canto II (BD Biosciences), and analyzed using FlowJo.

C5a measurements. $2 \times 10^{6}$ splenic DCs were cultured in $2 \mathrm{ml}$ serum-free HL-1 medium, and supernatants were concentrated using Amicon Ultra-0.5, NMWL $10 \mathrm{kDa}$ (Millipore Corp.), and tested for C5a by ELISA(R\&D Systems).

Immunoblots. Immunoblots for $\mathrm{C} 3$ were performed as described previously (14) using polyclonal goat anti-mouse C3 antibody (MP Biomedicals) and quantified using ImageJ software (NIH). 

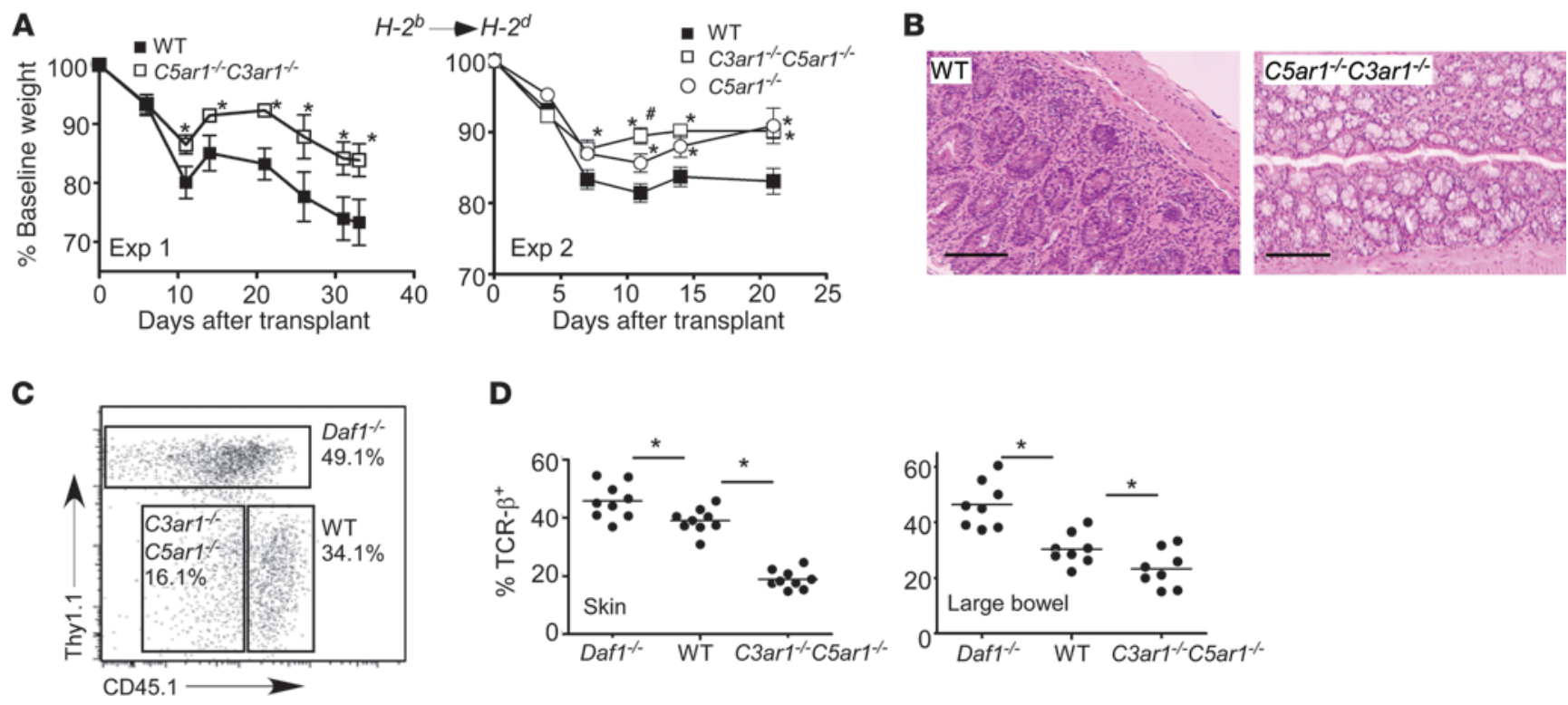

D
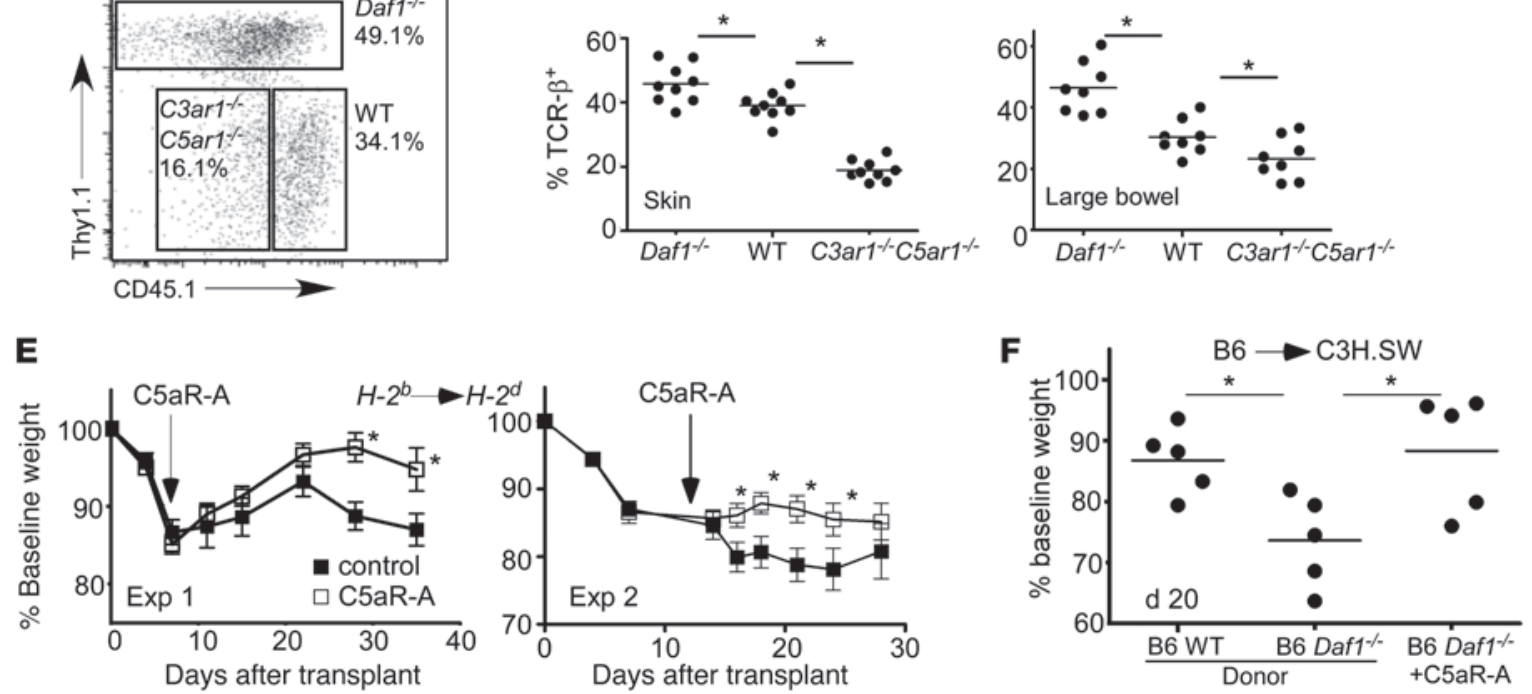

Figure 3

T cell-expressed C3aR and C5aR regulate in vivo T cell expansion and GvHD. (A) Weight change of BALB/c recipients of B6 BM plus $1.5 \times 10^{5}$ WT, C5ar1 $1^{-1-}$, or C3ar1 $1^{--}$C5ar1 $1^{--}$T cells in 2 experiments. $n=10-17$ per group per experiment. ${ }^{*} P<0.05$ versus WT, " $P<0.05$ versus $C 3 a r 1^{-1-}$ C5ar1 $1^{-1-}$. (B) H\&E-stained slides of large bowel (week 5) in recipients of WT or C3ar1 $1^{-1-C 5 a r 1^{-1}}$ T cells. Scale bars: $50 \mu \mathrm{m}$. (C and D) Representative flow cytometry (C) and quantitation (D) of skin- and large bowel-infiltrating T cells in a competition experiment. Irradiated BALB/c mice were injected

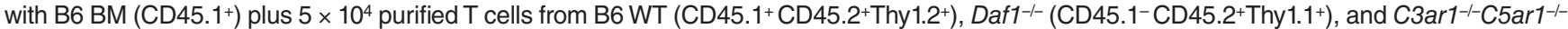
(CD45.1-CD45.2+ Thy 1.2+) mice. Assays were performed 5 weeks after transplantation (see Supplemental Figure 5 for gating) to determine normalized percentage of cells infiltrating the same skin and large bowel. $n=9$, pooled from 2 independent experiments. (E) Weights of BALB/c recipients of B6 BM and B6 $0.5 \times 10^{6}$ spleen cells with or without C5aR-A $(1 \mathrm{mg} / \mathrm{kg} / \mathrm{d})$ delivered beginning 7 or 14 days posttransplant by osmotic pump $(n=10-15$ per group). Clinical scores for experiment 1 at day 35 were as follows: control, $5.5 \pm 0.2$; C5aR-A, $3.8 \pm 0.2(P<0.05)$. (F) Weights of C3H.SW recipients of $\mathrm{mH}$-disparate $\mathrm{B} 6 \mathrm{BM}$ and $5 \times 10^{6}$ spleen cells with or without C5aR-A (initiated on day 0 ). $n=11-14$, pooled from 2 experiments. ${ }^{*} P<0.05$.

Real-time PCR. Splenic CD $11 \mathrm{c}^{+}$DCs or F4/80 hi macrophages were isolated by flow sorting. RNA isolation, cDNA synthesis, reverse transcription, and real-time RT-PCR were performed as described previously (13) using TaqMan (Applied Biosystems) primers. PCR products were normalized to the control gene (Mrp132) and expressed as fold increase compared with unstimulated cells using the $\Delta \Delta \mathrm{Ct}$ method.

Statistics. Data are presented as mean \pm SEM. Recipient survival was compared using log-rank survival statistics. Immunology assay results were compared using 2-tailed Student's $t$ test. In scatter-plot graphs, symbols denote individual mice or assays, and horizontal bars represent means. A $P$ value less than 0.05 was considered significant.

Study approval. All mice were housed in the Mount Sinai School of Medicine Center for Comparative Medicine and Surgery in accordance with guidelines of the Association for Assessment and Accreditation of Laboratory Animal Care International. The study protocols described herein were reviewed and approved by the Institutional Animal Care and Use Committee at Mount Sinai School of Medicine, New York, New York, USA.

\section{Acknowledgments}

We thank William Baldwin III and Nina Volokh (Cleveland Clinic, Cleveland, Ohio, USA) for assistance with C3d staining. The authors' work is supported by NIH grants AI/DK043578 (to P.S. Heeger), AI23598 (to M.E. Medof), CA112100, and HL086899 (to M. Merad) and by fellowship grants from the French Fondation de la Recherche Medicale (to W-.H. Kwan), the American Society of Transplantation (to W.-H. Kwan), and the National Kidney Foundation (to H. Raedler).

Received for publication September 15, 2011, and accepted in revised form April 4, 2012.

Address correspondence to: Peter S. Heeger, Mount Sinai School of Medicine, Annenberg Building Box 1243, One Gustave L. Levy Place, New York, New York 10029, USA. Phone: 212.241.6324; Fax: 212.987.0389; E-mail: peter.heeger@mssm.edu. 
1. Merad M, et al. Depletion of host Langerhans cells before transplantation of donor alloreactive T cells prevents skin graft-versus-host disease. Nat Med. 2004;10(5):510-517.

2. Shlomchik WD. Graft-versus-host disease. Nat Rev Immunol. 2007;7(5):340-352.

3. Shlomchik WD, et al. Prevention of graft versus host disease by inactivation of host antigen-presenting cells. Science. 1999;285(5426):412-415.

4. Zhang Y, Louboutin JP, Zhu J, Rivera AJ, Emerson SG. Preterminal host dendritic cells in irradiated mice prime CD8+ T cell-mediated acute graft-versus-host disease. J Clin Invest. 2002; 109(10):1335-1344.

5. Koyama M, et al. Plasmacytoid dendritic cells prime alloreactive $\mathrm{T}$ cells to mediate graft-versushost disease as antigen-presenting cells. Blood. 2009;113(9):2088-2095.

6. Wilhelm K, et al. Graft-versus-host disease is enhanced by extracellular ATP activating P2X7R. Nat Med. 2010;16(12):1434-1438.

7. Valenzuela JO, et al. PKCtheta is required for alloreactivity and GVHD but not for immune responses toward leukemia and infection in mice. J Clin Invest. 2009;119(12):3774-3786

8. Ma H, et al. Absence of Stat 1 in donor CD4+ T cells promotes the expansion of Tregs and reduces graft-versus-host disease in mice. J Clin Invest. 2011;121(7):2554-2569.

9. Bucher C, et al. IL-21 blockade reduces graft- versus-host disease mortality by supporting inducible $\mathrm{T}$ regulatory cell generation. Blood. 2009;114(26):5375-5384.

10. Chen X, et al. Blockade of interleukin- 6 signaling augments regulatory $\mathrm{T}$-cell reconstitution and attenuates the severity of graft-versus-host disease. Blood. 2009;114(4):891-900.

11. Heeger PS, et al. Decay-accelerating factor modulates induction of T cell immunity. J Exp Med. 2005;201(10):1523-1530.

12. Lalli PN, Strainic MG, Yang M, Lin F, Medof ME, Heeger PS. Locally produced C5a binds to T cellexpressed C5aR to enhance effector T-cell expansion by limiting antigen-induced apoptosis. Blood. 2008;112(5):1759-1766

13. Strainic MG, et al. Locally produced complement fragments $\mathrm{C} 5 \mathrm{a}$ and $\mathrm{C} 3 \mathrm{a}$ provide both costimulatory and survival signals to naive CD4+ T cells. Immunity. 2008;28(3):425-435.

14. Medof ME, Kinoshita T, Nussenzweig V. Inhibition of complement activation on the surface of cells after incorporation of decay-accelerating factor (DAF) into their membranes. J Exp Med. 1984;160(5):1558-1578

15. Hashimoto D, et al. Pretransplant CSF-1 therapy expands recipient macrophages and ameliorates GVHD after allogeneic hematopoietic cell transplantation. J Exp Med. 2011;208(5):1069-1082.

16. Lalli PN, Strainic MG, Lin F, Medof ME, Heeger PS. Decay accelerating factor can control $\mathrm{T}$ cell differ- entiation into IFN-gamma-producing effector cells via regulating local C5a-induced IL-12 production. JImmunol. 2007;179(9):5793-5802.

17. Bao L, Osawe I, Puri T, Lambris JD, Haas M, Quigg RJ. C5a promotes development of experimental lupus nephritis which can be blocked with a specific receptor antagonist. Eur I Immunol. 2005;35(8):2496-2506.

18. Hill GR, et al. Differential roles of IL-1 and TNFalpha on graft-versus-host disease and graft versus leukemia. J Clin Invest. 1999;104(4):459-467.

19. Cooke KR, et al. LPS antagonism reduces graft-versus-host disease and preserves graft-versus-leukemia activity after experimental bone marrow transplantation. J Clin Invest. 2001;107(12):1581-1589.

20. Peng Q, Li K, Patel H, Sacks SH, Zhou W. Dendritic cell synthesis of C3 is required for full T cell activation and development of a Th1 phenotype. J Immunol. 2006;176(6):3330-3341.

21. Zhang X, et al. Regulation of Toll-like receptormediated inflammatory response by complement in vivo. Blood. 2007;110(1):228-236.

22. Rittirsch D, et al. Functional roles for C5a receptors in sepsis. Nat Med. 2008;14(5):551-557.

23. Cooke KR, et al. An experimental model of idiopathic pneumonia syndrome after bone marrow transplantation: $\mathrm{I}$. The roles of minor $\mathrm{H}$ antigens and endotoxin. Blood. 1996;88(8):3230-3239.

24. Bogunovic M, et al. Origin of the lamina propria dendritic cell network. Immunity. 2009;31(3):513-525. 